International Journal of Advanced Chemistry, 2(2)(2014) 130-138
International Journal of Advanced Chemistry
Journal home page: $\begin{gathered}\text { www.sciencepubco.com/index.php/IJAC } \\ \text { doi: } 10.14419 / \text { ijac. } 2 \text { 2i2.2926 } \\ \text { Research Paper }\end{gathered}$
SPC

\title{
Novel gadolinium complexes in aqueous solution : characterization, identification and probable structures
}

\author{
M. Riri ${ }^{1}$, A. Benjjar ${ }^{1,2}$, O. Kamal ${ }^{1}$, M. Hor ${ }^{1}$, K. Touaj ${ }^{1}$, M. Hlaibi ${ }^{1,2}$ \\ ${ }^{1}$ Laboratory of Materials Interface and Chemistry of the Environment (LIME), Hassan II University, Faculty of Sciences, \\ Ain Chock, BP 5366, Maa rif, Casablanca, Morocco \\ ${ }^{2}$ Laboratory of Polymers, Biopolymers, Surfaces, UMR 6270 CNRS, University of Rouen, Faculty of Sciences, \\ F-76821 Mont-Saint-Aignan, France \\ *Corresponding author E-mail: medriri@gmail.com
}

\begin{abstract}
In this work, we shall present the results of investigations on the interaction of the gadolinium ion $\left(\mathrm{Gd}^{3+}\right)$ with different chelation sites of mandelic acid and DL-serine (amino acid) formed in dilute solution for $\mathrm{pH}$ values between 5.50 and 7.50. The general formula of these new organometallic complexes is and (mandelate ions and: serine ions). These gadolinium complexes detected, are colorless and have no absorption band UV-visible. In this sense, we have used an analytical technique called « Indirect Photometry Detection (IPD) » have identified major di-nucleaire and tri-nuclear complexes of these acids. This technique allowed us to determine the composition and stabilities of complexes predominate in solution, giving for these colorless complexes a molar ration (2:2) and (3:2) for mandilic acid and serine acid respectively, and we have shown that the composition and stability constant depends on the acidity of the medium. To complement previous results and to propose probable structures for these new coloress complexes, IR and Raman spectroscopy have been conducted to identify the different chelation sites for theses ligands.
\end{abstract}

Keywords: Coloress Complexes, DL-Serine, Indirect Photometry Detection, Gadolinium Complexes, Mandelate Ions.

\section{Introduction}

Currently, gadolinium complexes are commonly used to improve the contrast of images obtained by MRI (Magnetic Resonance Imaging). However, gadolinium ion is highly toxic in its hydrated form $\left[\mathrm{Gd}\left(\mathrm{H}_{2} \mathrm{O}\right)_{8}\right]^{3+}$, its complexation with an organic ligand reduces this toxicity. This complexation should be administered in the form thermodynamically very stable [1]. The solution consists of enclosing the gadolinium ion in the linear or cyclic organic ligands to form complex non-toxic, inert and stable in the body [2]. The most widely ligands used are polyaminocarboxylates and their derivatives. In this work we have studied the formation of colorless gadolinium complexes with some linear ligands in dilute solutions. To study of these colorless complexes, we developed à new analytical technique for determining the compositions and stabilities of some colorless organometallic complexes, which have no absorption band UV-visible. This technique is the indirect photometry detection (IPD), based on competitive reactions by ligand-ligand exchange. The method is simple, reproducible, effective and applicable to very dilute solutions. Thus, the importance of IPD technique was also revealed by its adaptation to other techniques of separation and determination, such as liquid chromatography [3], [4], capillary electrophoresis [5] and continuous flow analysis (FIA) [6]. Some studies show that this technique is very effective in identifying some colorless gadolinium [7], [8], [9] and tungstate complexes of sugars and organic acids [10]. The detection or monitoring of certain diseases, sometimes requires injection gadolinium complexes because of the interesting electro nic and magnetic properties of this ion [11], [12]. The most contrast agent used in MRI are complexes of amino acids and carboxylic acids with some lanthanides [13]. Currently, most contrast agents used in MRI are complexes of gadolinium-DTPA, gadolinium-BOPTA, gadolinium-DOTA [14-17] and its analogs which are modified to enhance the contrast effect on fabric [18], [19]. Other studies have shown that gadolinium complexes of coumarin-3-carboxylic acid(2-oxo-2H-chromene-3-carboxylic acid) and its derivatives have very important pharmaco- logical properties [20]. In this work, investigations by indirect photometry detection (IPD) were carried out to study the interaction of the trivalent gadolinium ions, with conjugate base of mandelic acid and DLserine ions), detecting the majority of colorless complexes formed in solution and determining their composition and stability. To elucidate the structure and the chelation sites of these major complexes, the technique FT-IR and FT-Raman spectroscopy has been used fruitfully. Indeed, these three techniques (IPD, IR and Raman spectroscopy) are very useful for elucidating the formation of the major complexes for the systems (Gd(III)-mandelate acid and Gd(III)-serine), hence, help precisely determine the composition, stability and the nature of chelation sites for each of ligands, involved in the composition of detected complexes and propose probable structures for these new complexes. The acidity constants and semi developed form of mandelic acid and serine are noted in the Table 1 [21], [22]. 
Table I: Some Characteristics Of Acids Studied

\begin{tabular}{|c|c|c|c|}
\hline Acid & Chemical formula & $\mathrm{pKa}_{1}$ & $\mathrm{pKa}_{2}$ \\
\hline Mandelic & $\mathrm{C}_{6} \mathrm{H}_{5}-\mathrm{CH}(\mathrm{OH})-\mathrm{COOH}$ & 3.50 & ------ \\
\hline Serine & $\mathrm{HOCH}_{2}-\mathrm{CH}\left(\mathrm{NH}_{2}\right)-\mathrm{COOH}$ & 2.19 & 9.91 \\
\hline
\end{tabular}

\section{Experimental section}

\subsection{Chemicals}

Mandelic acid, DL-serine, Chrome Azurol S ( $\left.\left(\mathrm{H}_{4} \mathrm{Ch}\right)\right)$, Gd(III) nitrate and other chemicals were commercial products (Aldrich, Prolabo) of the purest available and analytical grade, used as received.

\subsection{Indirect photometric detection}

A standard Helios $\gamma \mathrm{UV}$-visible spectrometer controlled by Vision 32 software was used for spectrometric measurements, using quartz cells of optical path length $l=1 \mathrm{~cm}$. The absorption measurements have been performed at room temperature and at wavelength $\lambda_{\max }=545 \mathrm{~nm}$. Stock solutions of $\mathrm{Gd}(\mathrm{III})$ nitrate and Chrome Azurol S $\left(\left(\mathrm{H}_{4} \mathrm{Ch}\right)\right)$, were prepared with concentrations of respectively $10^{-2} M$ and $10^{-3} M$. In a typical experiment, a solution $(v=50 \mathrm{~mL})$ of the colored sacrificial complex $\left(G d-H_{4} C h\right)$ was prepared $\left(\left[G d^{3+}\right] /\left[H_{4} C h\right]=1.5\right.$, using it as a buffer of MESH $(0.1 \mathrm{M})$ [2-(N-morpholino) sulfonic ethane acid]. The initial solution also contained a calculated amount of 1 $\mathrm{M} \mathrm{NaOH}$ in order to obtain the desired $\mathrm{pH}$ value $(\mathrm{pKa}(\mathrm{MESH})=$ 6.2 , experimental $\mathrm{pH}$ range $(5.50-7.50)$. $\mathrm{pH}$ values are measured with a microprocessor $\mathrm{pH}$ meter HANNA 210 equipped with a combined electrode glass and calibrated with commercial buffers (pH 4.00 and 7.00). Then aliquots $(v=0.100-0.200 m L)$ of an aqueous solution of the mandelic acid and DL-serine ( $C_{L}=10 \mathrm{~g} / \mathrm{L}$ and $C_{L}=20 \mathrm{~g} / \mathrm{L}$ respectively) were added, using a Gilson micropipet of $0.200 \mathrm{ml}$. After each addition, the resulting solution was left at least $2 \mathrm{~min}$ in order to reach equilibrium (and thus a constant absorption value). Addition was repeated until a maximum volume of $4.00 \mathrm{ml}$ of the ligands solution was added The change in the total volume was neglected. For fixed $\mathrm{pH}$ environments, the apparent formation constants $\log K^{\prime}{ }_{x y z}$ was calculated from the equilibrium of the reaction of formation of these complexes. The absorption values for the undissociated $\left(\mathrm{A}_{\mathrm{F}}\right)$ and the totally dissociated $\left(\mathrm{A}_{\mathrm{I}}\right)$, sacrificial complex $\left(\mathrm{Gd}-\mathrm{H}_{4} \mathrm{Ch}\right)$, are used as determined in experiments using pure Chrome Azurol $\mathrm{S}$ ( $\mathrm{H}_{4} \mathrm{Ch}$ ), and an excess of Gadolinium(III) (performed at $\mathrm{pH}$ intervals of 0.25). Assuming various integers for the Gadolinium and organic acids stoichiometry, a formation constant is calculated for each added amount of ligands and corresponding absorption value. The results are rejected when a systematic variation of $\log K_{x y z}{ }_{z}$ occurs with increasing added-up amount of ligands or when individual values of $\log K^{\prime} x y z$ differed from the mean value by more than $2 \%$.

\subsection{IR spectroscopy}

Samples were prepared by weighing the appropriate amount of mandelic acid and DL-serine (ligands) and $\left(\mathrm{Gd}\left(\mathrm{NO}_{3}\right)_{3} \cdot 6 \mathrm{H}_{2} \mathrm{O}\right)$ adding $\mathrm{H}_{2} \mathrm{O}$, mixing and finally adjusting the $\mathrm{pH}$ with concentrated $\mathrm{HCl}$ or $\mathrm{NaOH}$. Concentrations of analyzed samples are $10^{-3} M$. Analyses were performed using an infrared spectrometer, Fourier transform (FT-IR) Perkin Elmer BX, equipped with a DTGS detector, a splitter and a cesium iodide window. In this configuration, the interval of analysis is that the middle infrared, $6000-250 \mathrm{~cm}^{-1}$ and analysis are conducted on small samples, whose size is less than $1 \mathrm{~mm}^{3}$. Liquid samples are placed between two plates of very pure salt $(\mathrm{KBr})$, these platesare transparent to infrared light and the spectra relative to free ligands and complexes have been plotted for frequencies $4400-400 \mathrm{~cm}^{-1}$.

\subsection{RAMAN spectroscopy}

The complexes are precepitated quickly at room temperature, at a concentration of $10^{-2} \mathrm{M}$ and fixed $\mathrm{pH}$ values. The precipitates were filtered, and dried in a drying oven. The Raman spectra of the studied ligands and their new Gd(III) complexes were performed using a Raman spectrometer Fourier transform (FT-Raman) VERTEX 70 with a range of measurement $4000-50 \mathrm{~cm}^{-1}$, laser source NdYag $(1.064 \mu \mathrm{m})$, a nominal power of $500 \mathrm{MW}$, detecting Ge with high sensitivity and a resolution of $4 \mathrm{~cm}^{-1}$ (64 scan). The spectra relative to free ligands (acids) and complexed (Gd(III) -Acids), have been plotted for frequencies from 4000 to $150 \mathrm{~cm}^{-1}$.

\section{Results and discussion}

\subsection{Indirect photometric detection study}

\subsubsection{Expression of the stability constant of mandelic acid}

The complexation reaction of gadolinium ions with mandelic acid and protons, is given by general reaction (I) :

$x G d^{3+}+y L^{-}+z H^{+} \rightleftarrows(x, y, z)+n H_{2} \mathrm{O}$

- $\quad \mathrm{L}^{-}$represents the ligand (mandelate).

- We noted $(\mathrm{x}, \mathrm{y}, \mathrm{z})$ to simplify the writing of complex formed.

- $\quad \mathrm{x}, \mathrm{y}$ and $\mathrm{z}$ are, respectively, the stoichiometric coefficients relating to the $\mathrm{Gd} 3+$ ion, acid studied in its basic form and the number of protons $\mathrm{H}+$ involved in complexation reaction.

The formation constant $K_{x y z}$ (or stability constant $\beta_{\mathrm{xyz}}$ ) of the complexes are defined as the equilibrium constant :

$K_{x y z}=[(x, y, z)] /\left[G d^{3+}\right]^{x} \cdot\left[L^{-}\right]^{y} \cdot\left[H^{+}\right]^{z}$

Additionally, à conditional equilibrium constant $K^{\prime}{ }_{x y z}$ is defined in case of constant $\mathrm{pH}$ value (buffered solution) :

$K_{x y z}^{\prime}=[(x, y, z)] /\left[G d^{3+}\right]^{x} \cdot\left(\mathrm{C}_{L}\right)^{y}=K_{x y z} \cdot\left[H^{+}\right]^{z}$

Where $C_{L}$ represents the analytical concentration of the uncomplexed ligand, all experiments are performed for $\mathrm{pH}$ values higher than $\mathrm{pK}_{\mathrm{a} 1}$ mandelic acid. Therefore, we have $C_{L}=\left[L^{-}\right]$. Using this equality, Eq. (1) can be written as:

$K_{x y z}^{\prime}=[(x, y, z)] /\left[G d^{3+}\right]^{x} \cdot\left[L^{-}\right]^{y}$

And

$K_{x y z}^{\prime}=K_{x y z} \cdot\left[H^{+}\right]^{z}$

Thus

$\log K_{x y z}=\log K_{x y z}^{\prime}=z \cdot p H$ 


\subsubsection{Expression of the stability constant of aminoacid (serine)}

In general, amino acids exhibit several forms depending on the $\mathrm{pH}$ of the medium, so we expressed stability constatnte from the major form of serine to working $\mathrm{pH}$ range $(\mathrm{pH} 5.50-7.50)$. The complexation reaction of serine with gadolinium ions is as follows :

$x \mathrm{Gd}^{3+}+y \mathrm{R}\left(\mathrm{NH}_{2}\right) L^{-}+z \mathrm{H}^{+} \rightleftarrows(x, y, z)+n \mathrm{H}_{2} \mathrm{O}$

$\left.\begin{array}{lll}R\left(\mathrm{NH}_{2}\right) L^{-} & \mathrm{R}\left(\mathrm{NH}_{2}\right) & \mathrm{L}^{-}\end{array}\right] \quad$ is the the form

$\mathrm{HOCH}_{2}-\mathrm{CH}_{2}\left(\mathrm{NH}_{2}\right) \mathrm{CO}_{2}{ }^{-}$

The stability constatnt is defined by Equation 6 :

$K_{x y z}=[(x, y, z)] /\left[G d^{3+}\right]^{x} \cdot\left[R\left(N H_{2}\right) L^{-}\right]^{y} \cdot\left[H^{+}\right]^{z}$

The different forms of serine are $\mathrm{HOCH}_{2}-\mathrm{CH}_{2}\left(\mathrm{HNH}_{2}{ }^{+}\right) \mathrm{CO}_{2} \mathrm{H}$, $\mathrm{HOCH}_{2}-\mathrm{CH}_{2}\left(\mathrm{HNH}_{2}{ }^{+}\right) \mathrm{CO}_{2}{ }^{-}$and $\mathrm{HOCH}_{2}-\mathrm{CH}_{2}\left(\mathrm{NH}_{2}\right) \mathrm{CO}_{2}{ }^{-}$. While the analytical concentration of serine in the solution is given by :

$$
\begin{aligned}
& \mathrm{C}_{\mathrm{L}}=\left[\mathrm{HOCH}_{2}-\mathrm{CH}_{2}\left(\mathrm{NH}_{2}\right) \mathrm{CO}_{2}{ }^{-}\right] \\
& +\left[\mathrm{HOCH}_{2}-\mathrm{CH}_{2}\left(\mathrm{HNH}_{2}{ }^{+}\right) \mathrm{CO}_{2}{ }^{-}\right] \\
& +\left[\mathrm{HOCH}_{2}-\mathrm{CH}_{2}\left(\mathrm{HNH}_{2}{ }^{+}\right) \mathrm{CO}_{2} \mathrm{H}\right]
\end{aligned}
$$

For $\mathrm{pH}$ values between $\mathrm{K}_{\mathrm{a} 1}=2.19$ and $\mathrm{K}_{\mathrm{a} 2}=9.91$, the ions $\mathrm{HO}-\mathrm{CH}_{2}-\mathrm{CH}_{2}\left(\mathrm{HNH}_{2}{ }^{+}\right)-\mathrm{COO}^{-}$predominate in the solution. Then the analytical concentration $\mathrm{C}_{\mathrm{L}}$ is expressed from the following major form $\mathrm{HOCH}_{2}-\mathrm{CH}_{2}\left(\mathrm{HNH}_{2}{ }^{+}\right) \mathrm{CO}_{2}{ }^{-}$.

$$
\begin{aligned}
& \mathrm{C}_{\mathrm{L}}=\left[\mathrm{HOCH}_{2}-\mathrm{CH}_{2}\left(\mathrm{HNH}_{2}{ }^{+}\right) \mathrm{CO}_{2}{ }^{-}\right] \\
& =\left[\mathrm{HOCH}_{2}-\mathrm{CH}_{2}\left(\mathrm{NH}_{2}\right) \mathrm{CO}_{2}{ }^{-}\right] \times\left[\mathrm{H}^{+}\right] / \mathrm{K}_{a 2}
\end{aligned}
$$

Therefore, the stability constant given by equation (6) has become in this expression:

$$
\begin{aligned}
& K_{x y z}=[(x, y, z)] /\left[G d^{3+}\right]^{x} \\
& \times(C L)^{y} \times\left(K_{a 2}\right)^{y} \times\left[H^{+}\right]^{z-y} \\
& \left.=K^{\prime}{ }_{x y z} \times\left[H^{+}\right]^{-(z-y)} \times K_{a 2}\right)^{-y}
\end{aligned}
$$

And

$\log K^{\prime}{ }_{x y z}=\log K_{x y z}-y \cdot p K_{a 2}-(z-y) \times p H$

In the first stage of the characterization of the gadolinium ion complexes with acids studied, we determined the compositions $\mathrm{x}$, $\mathrm{y}, \mathrm{z}$ and stabilities constants of these colorless complexes. The complexation of the ligands (acids studied) can be studied using a spectrophotometric method. Since the reagents (mandelic acid and serine) and their gadolinium complexes don't possess a characteristic UV-visible absorption spectrum, a second ligand (called the sacrificial ligand) is introduced, this ligand must absorb in the UV-visible spectrum and form a colored complex with gadolinium(III). The dissociation of this colored complex has to cause large variations in the UV-visible spectrum which allows for the calculation of the concentration of the sacrificial complex; using the formation constant of this colored complex, the concentration of the unknown complex can be obtained. Therefore, the sacrificial ligand must form a single colored complex of lower stability than the gadolinium complex under study. In this work, Sulfo- 3 "dichloro-2",6"dimethyl-3,3'-hydoxy-4'-fuchsone-5,5'-

dicarboxylic acid, often called Chrome Azurol S and notable $\mathrm{H}_{4} \mathrm{Ch}$, has been used as sacrificial ligand. Chrome Azurol S is a tetraprotic acid with pKa values of $2.25\left(\mathrm{H}_{3} \mathrm{Ch}^{-} /\left(\mathrm{H}_{2} \mathrm{Ch}^{-}\right), 4.71\right.$
$\left(\mathrm{H}_{2} \mathrm{Ch}^{2-} / \mathrm{HCh}^{3-}\right)$ and $11.82\left(\mathrm{HCh}^{3-} / \mathrm{Ch}_{4}{ }^{-}\right)$(Langmyhr \& Klausen, 1963). In the experimental $\mathrm{pH}$ range (5.50-7.50), the formation of $\mathrm{H}_{4} \mathrm{Ch}, \mathrm{H}_{3} \mathrm{Ch}^{-}$and $\mathrm{H}_{2} \mathrm{Ch}^{2-}$ has been neglected. It is an indicator which is generally used for the photometric proportioning of the metal ions in solution (Dona \& Verchere, 1991). The interaction of the $\mathrm{H}_{4} \mathrm{Ch}$ with gadolinium ions $\left(\mathrm{Gd}^{3+}\right)$, gives a colored reagent $\left(\lambda_{\max }=545 \mathrm{~nm}\right.$ ) of average stability for values of pH ranging between 5.50 and 7.50. The buffer "MESH'. [2(N-Morpholino) sulfonic ethane acid] was adopted to fix $\mathrm{pH}$ in the study of the sacrificial complex (Gadolinium- $\mathrm{H}_{4} \mathrm{Ch}$ ) and gadolinium-Ligands complexes studied in this work. We chose this buffer because it does not present any interaction with $\mathrm{Gd}^{3+}$ ions and so we would be able to work in the range of $\mathrm{pH}$ where the stability of the sacrificial complex is maximal.

\subsection{Formation of the colored sacrificial complex $G d_{x}(H C h)_{y}$}

The majority of organometallic complexes studied are colorless. Thus the study of the formation of the sacrificial complex $G d_{x}(H C h)_{y}$ is very important, because this steps decisive parameters (composition and stability) of these new gadolinic complexes. In this sense and in the my works published [7-10] we have demonstrated, experimentally, that the composition and stability of the colored sacrificial complex were determined, we found a complex type $(3,2,3)$ and stability constant $\log K_{323}=16.27$ in $\mathrm{pH}$ range $5.50-7.50$, and the probable reaction for this complex faormation is :

$3 \mathrm{Gd}^{3+}+2 \mathrm{HCh}^{3-}+3 \mathrm{H}^{+} \rightleftarrows(3,2,3)+n \mathrm{H}_{2} \mathrm{O}$

We use these results (sacrificial complex) to study two organometallic complexes $\mathrm{Gd}$-mandelate and $\mathrm{Gd}$-serine.

\subsection{The composition and stability of the Gd (III)-Acids system studied}

The ligands are added to a colored solution containing sacrificial complex $\mathrm{Gd}_{3} \mathrm{HCh}_{2}$ and this Chrome Azurol complex will dissociate under effect of added ligands. To calculate the complex concentration of the $\mathrm{HCh}^{3-}$ ions, the absorption values of the totally complexed $\left(\mathrm{A}_{\mathrm{F}}\right)$, and the completely dissociated $\left(\mathrm{A}_{\mathrm{I}}\right) \mathrm{HCh}^{3-}$ ions have to be determined. Then the following equations can be used : $[(x, y, z)]=\alpha \times C_{L}=C_{L} \cdot\left(A-A_{I}\right) /\left(A_{F}-A_{I}\right)$

A coefficient of sacrificial complex formation and $\left.\alpha=\left(A-A_{I}\right) / A_{F}-A_{I}\right)$ and $C_{L}=C_{H C h}$

$\left[\mathrm{HCh}^{3-}\right]_{\text {free }}=C_{L} \times\left(A_{F}-A\right) /\left(A_{F}-A_{I}\right)$

When the conditional constant $\mathrm{K}_{323}^{\prime}$ of the sacrificial complex is known, the concentration of free gadolinium ion $\left(\left[G d^{3+}\right]\right)$, can be calculated using Equations (9) and (10). Knowing the two concentrations $[(3,2,3)]$ and $\left[G d^{3+}\right]$, the concentration of the gadolinium complex under study $[(\mathrm{x}, \mathrm{y}, \mathrm{z})]$ (balanced reaction $\mathrm{I})$ can be determined using the gadolinium balance equation :

$x \cdot[(x, y, z)]=C_{G d}-\left[G d^{3+}\right]_{\text {free }}-3[(3,2,3)]$

$\mathrm{C}_{\mathrm{Gd}}$ the initial gadolinium concentration and $[(\mathrm{x}, \mathrm{y}, \mathrm{z})]$ the concentration of coloress complex formed.

In à similar way, the concentration of the free ligand is obtained by Eq. (12) :

$\left(C_{L}^{n-}\right)_{\text {free }}=\left(C_{L}^{n-}\right)_{\text {initial }}-y[(x y, z)]$ 
It should be also noted that a perfect knowledge of the characteristics of the sacrificial colored complex $\left(\mathrm{Gd}_{3} \mathrm{HCh}_{2}\right)$ is necessary. The determination of the composition and the stability of the sacrificial complex and the precision of the conditions of its formation are paramount stages to apply the indirect photometry detection.

In each experiment, the ligands $\left(\mathrm{C}_{6} \mathrm{H}_{5}-\mathrm{CH}(\mathrm{OH})-\mathrm{COO}^{-}\right.$(mandelate) and $\left(\mathrm{HOCH}_{2}-\mathrm{CH}\left(\mathrm{NH}_{2}\right)-\mathrm{COO}^{-}\right)$(serine completely deprotonate)) are added stepwise in order to measure the absorption at different values (at least 13) of the overall initial concentration of these studied ligands. The correct $K_{x y z}^{\prime}$ is looked for by varying $\mathrm{x}$ and $\mathrm{y}$ in order to obtain a constant for all values of $C_{L}^{n-}$. If $\log K_{x y z}^{\prime}$ is determined at different $\mathrm{pH}$, the slope of the $\log K_{x y z}^{\prime}=f(p H)$ plot reveals the number $\mathrm{z}$ of protons that is very necessary for the formation of the studied gadolinium complexes by the use of Eq. (4) and Eq. (8), since the value of $K_{x y z}$ is independent of $\mathrm{pH}$. Now the stability and the total composition of the gadolinium complexes have been determined.

\subsection{Determination of the composition and the stability constant of these new gadolinic complexes}

With an aim of determining the composition and the stability constant of the gadolinium-mandelate and gadolinium-serine complexes, we monitoring the evolution of the absorbance during the disappearance of the sacrificial complex by the addition of increasing quantities of ligands. For a given volume $(50 \mathrm{~mL}$ or $100 \mathrm{~mL})$ of a solution containing sacrificial complex $(3,2,3)$ $\left(10^{-4} M\right)$, we added increasing quantities of acids studied, with known concentration. The spectrophotometric study carried out with fixed wavelength ( $\lambda_{\max }=545 \mathrm{~nm}$ ), showed a reduction in the absorbance of the solution progressively with the addition of the acids (Figure 1). The dissociation of the sacrificial complex, relating to the reduction in the absorbance by the addition of mandelate and serine ions solution, is done in favor of the formation of the colorless complex between $\mathrm{Gd}^{3+}$ and acids studied. The curves $\mathrm{C} 1$ and $\mathrm{C} 2$, in Figure 1, of systems Gd-serine and $\mathrm{Gd}-$-mandelic acid respectively, clearly show that the absorbance decreases and stabilizes. This stability indicates that all $\mathrm{Gd}^{3+}$ ions, initially present in the solution have reacted to added ligands ions. Knowing the concentration of gadolinium ions and the quantity of ligands (added volume of acids solution), necessary to reach this stage of absorption, we could determine the molar ratio $\boldsymbol{q}=[\boldsymbol{G d}(\boldsymbol{I I I})] /[$ Acid $]$, involved in the complexation reaction.

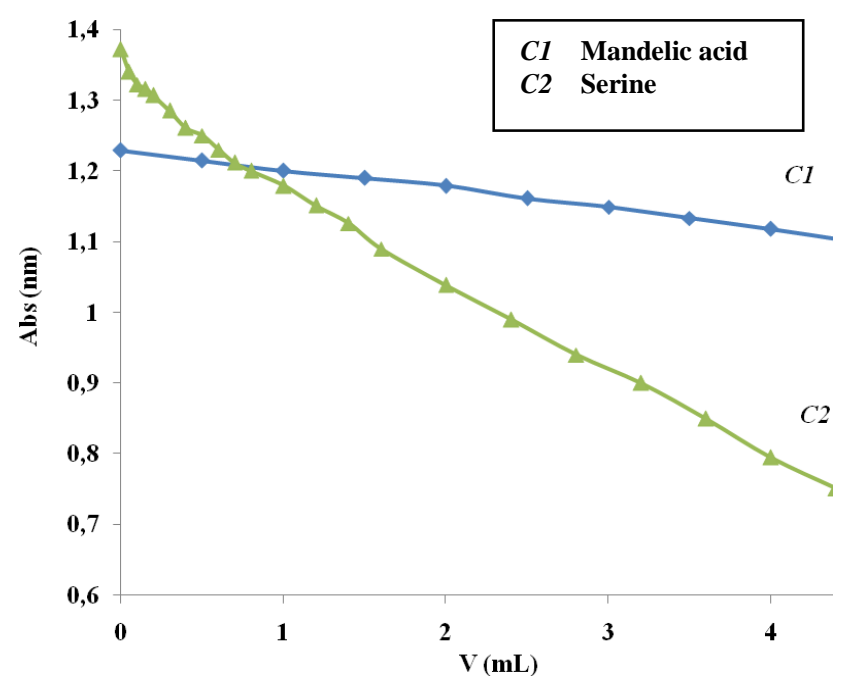

Fig. 1: Decomposition of Colored Sacrificial Complex by Addition of Mandelic Acid and SerineMass concentration of mandelic acide and serine $10 g / L$ and $20 g / L$ respectively.

The preceding experiment was carried out for different values of $\mathrm{pH}$ between 5.50 and 7.50, the way in which the absorption decreases, depends on the $\mathrm{pH}$ of the medium and on the formation constant of the detected complex (Gd-Acid), as well as on the absorption values $\left(\mathrm{A}_{\mathrm{I}}\right)$ and $\left(\mathrm{A}_{\mathrm{F}}\right)$ of the free and totally complexed Chrome Azurol S ( $\mathrm{HCh}^{3-}$ ). Analyzing the experimental data with the computer program written from the balanced reaction (I), the results confirm the reproducibility of the molar ratio " $q$ " and to determine the composition and the stability constant $K_{x y z}^{\prime}$. The ratio $q=\left(\left[G d^{3+}\right] /[\right.$ acid $\left.]\right)=x / y$ is determined experimentally from a computer program written in Microsoft Excel and expressed from the reaction of complex (reaction I). This program is not a theoretical modeling. But this is a translation of the reaction steps of the balance (I) for ease of calculation. Figure 2 Represents an example of calculating the ratio $\mathrm{q}$ at $\mathrm{pH} 6.40$ of serine complexed with gadolinium ion, where we inserted the two experimental values : the volumes added $\left(V_{a}\right)$ of ligand and the absorbance (A) correspond for each added volume $V_{a}$ of ligand, to seek the values of $\mathrm{x}$ and $\mathrm{y}$ to the value of conditional constant $\left(\log K_{x y z}^{\prime}\right)$ which remains constant. The calculations are repeated for different experimental $\mathrm{pH}$ between 5.50 and 7.50.

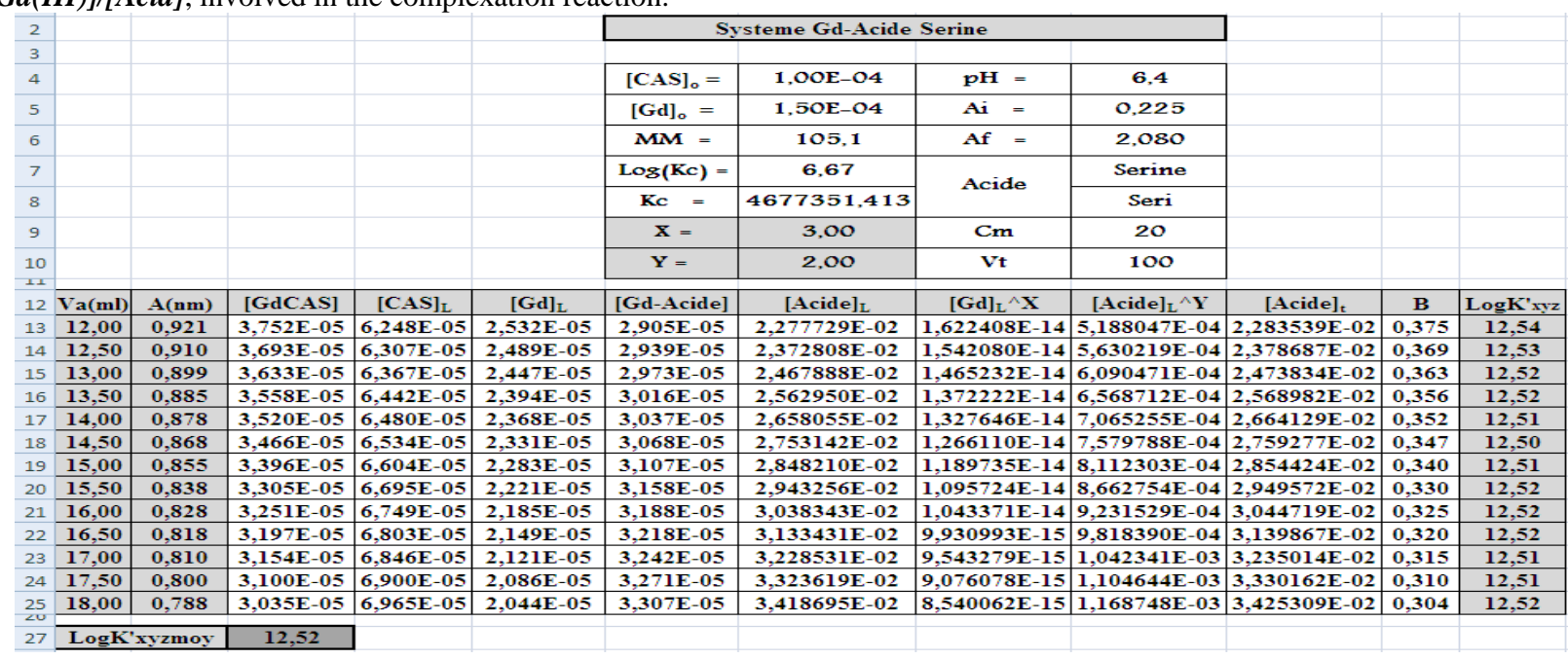

Fig. 2: Example of Program Used to Calculate the Compositions X, Y and The Stability $\log K_{x y z}$ 
$\boldsymbol{C m}$ : Mass concentration of serine acid (20g/l), $\boldsymbol{V} \boldsymbol{a}$ added volume of Seine, A experemantal absorbance, Kc : constant of colored sacrificial complex, $\log \mathrm{K}^{\prime} \mathrm{xyz}=12.52 \mathrm{q}=\mathrm{x} / \mathrm{y}=3 / 2$ and $\mathrm{pH}=6.40$.

We obtained a molar ratio $q=x / y$ for mandelic acid equal 2:2 and 3:2 for serine. The data-processing treatment of the preceding experimental results, shows that these di and tri-nuclear detected complexes are formed between the gadolinium ions and ligands, resulting from the interaction of two $\mathrm{Gd}(\mathrm{III})$ ions equivalents with two equivalents of mandelate species and three Gd(III) ions for serine, so a molar ratio $q=x\left(G d^{3+}\right) / y\left(L^{-}\right)$remains the same for each of the each complexes detected for a fixed conditional constant $\left(\log K_{x y z}^{\prime}\right)$ in $\mathrm{pH}$ range between 5.50 and 7.50. The constants and the molar ratio $\mathrm{q}$ at differents values of $\mathrm{pH}$ are given in Table 2.

Table II : The Conditional Stability of the Di and Tri-Nuclear Complexes Detected, Depending on the Acidity of the Medium.

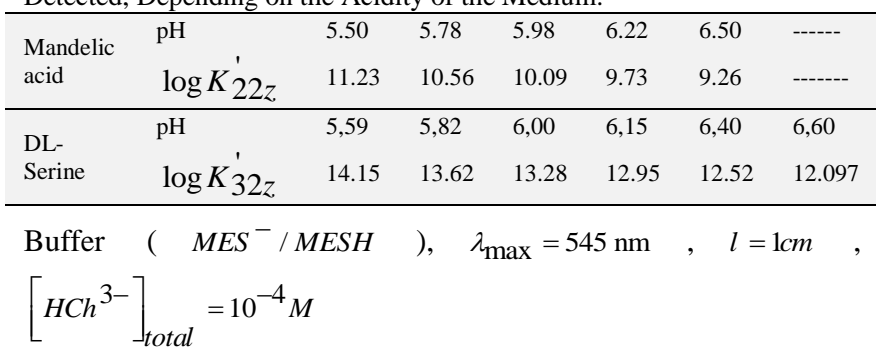

Therefore, for the complexation reaction of $\mathrm{Gd}^{3+}$ ions with mandelate and serine ions at this $\mathrm{pH}$ range, these results, the reactions (I) and (II) and the equtions (2), (4), (5), (7) and (8) allow us to write the following expressions.

\subsubsection{Mandelic acid}

$$
\begin{aligned}
& 2 \mathrm{Gd}^{3+}+2 L^{-}+z H^{+} \rightleftarrows(2,2, z)+n \mathrm{H}_{2} \mathrm{O} \\
& K_{22 z}^{\prime}=[(2,2, z)] /\left[G d^{3+}\right]^{2} \cdot\left(\mathrm{C}_{L}\right)^{2}=K_{22 z} \cdot\left[H^{+}\right]^{z} \\
& \log _{22 z}^{\prime}=\log K_{22 z}-z \times p H
\end{aligned}
$$

\subsubsection{Serine}

$$
\begin{aligned}
& 3 \mathrm{Gd}^{3+}+2 \mathrm{R}\left(\mathrm{NH}_{2}\right) \mathrm{L}^{-}+z \mathrm{H}^{+} \longleftrightarrow(3,2, z)+n \mathrm{H}_{2} \mathrm{O} \\
& K_{32 z}=\left[(3,2, z] /\left[G d^{3+}\right]^{3} \cdot\left[R\left(\mathrm{NH}_{2}\right) L^{-}\right]^{2} \cdot\left[H^{+}\right]^{z}\right. \\
& =K^{\prime}{ }_{32 z} \times\left[H^{+}\right]^{-(z-2)} \times K_{a 2}^{-2} \\
& \text { and } \\
& \log ^{\prime}{ }^{\prime}{ }_{32 z}=\log _{x y z}-2 p K_{a 2}-(z-2) p H
\end{aligned}
$$

For the three complexes detected, the results in table 2 combined with equations (14) and (16) allow to plot functions $\log K{ }^{\prime} 22 z=f(p H)$ and $\log ^{\prime}{ }^{\prime} 32 z=f(p H)$, hence determine the number $\mathrm{z}$ of protons $\mathrm{H}^{+}$involved in the reaction obtained from the straight lines. The evolution of $\log K_{x y z}^{\prime}$ at different $\mathrm{pH}$ values is represented in Figure 3.

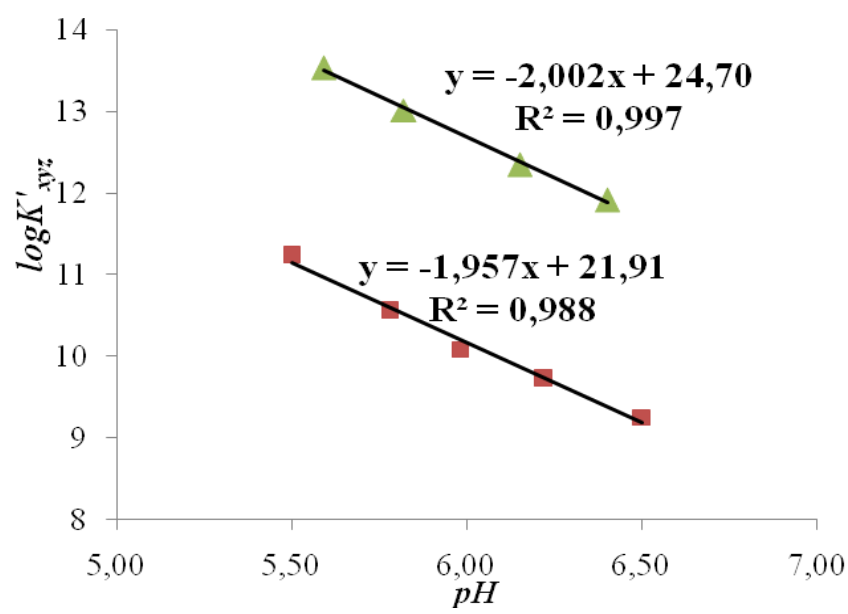

Fig. 3 : The Evolution of $\operatorname{Logk}_{x y z}$ at Different Ph Values.

$\triangle$ : Complex Gd-Serine and $\square$ : Complex Gd-Mandelate

This evolution is linear and the slope $\mathrm{p}$ of the straight line is equal to -2 for each gadolinium complexes. The value of $z=-p=2$ for Gd-Mandelate and for Gd-Serine $p=-2=-(z-2)$ (Eq.17 than $z=4$ ) represents the number of protons involved in the formation reaction of these new multi-nuclear complexes [di-nulear $(2,2,2)$ for Gd-Mandelate and tri-nuclear complex $(3,2,4)$ for $\mathrm{Gd}-$ Serine]. The Equations (14) and (16) allowed us to calculate the stability constants $\log K_{x y z}$ theses two complexes, the experimental results obtained by the IPD for Gd-Mandelate is $\log K_{222}=21.91 \pm 0.01 \quad$ and $\mathrm{Gd}-$ Serine $\log K_{324}=43.71 \pm 0.015$.

Consequently, the spectrophotometric results concerning the interaction of the $\mathrm{Gd}(\mathrm{III})$ ion with mandelate show that the complexation reaction uses two Gd(III) ions, two carboxylates and fixation of two $\mathrm{H}^{+}$protons, but in the case of complex $\mathrm{Gd}-$ Serine, there are three Gd(III) ions interact with two ligands (two serine) and the intervention of four protons $\mathrm{H}^{+}$. In order to confirm our results, to have more information on the nature of these new gadolinium complexes and likely to propose a probable structure for these di and tri-nuclear coloress complexes, we carried out IR and Raman spectroscopy investigations.

\section{IR and raman spectroscopic studies}

The IR and Raman spectroscopic studies are used to identify different groups of ligands involved in chelation sites of gadolinium complexes detected in solution. The interpretations of spectra, help to identify the main bands related to vibration frequencies of the various functions of free acids studied and their gadolinic complexes and to suggest correct structures for theses two studied in this work.

\subsection{Infrared spectra}

An example of IR spectra has been registered for the free and complexed form of mandelic acid, the spectra obtained are shown in Figure 4. 

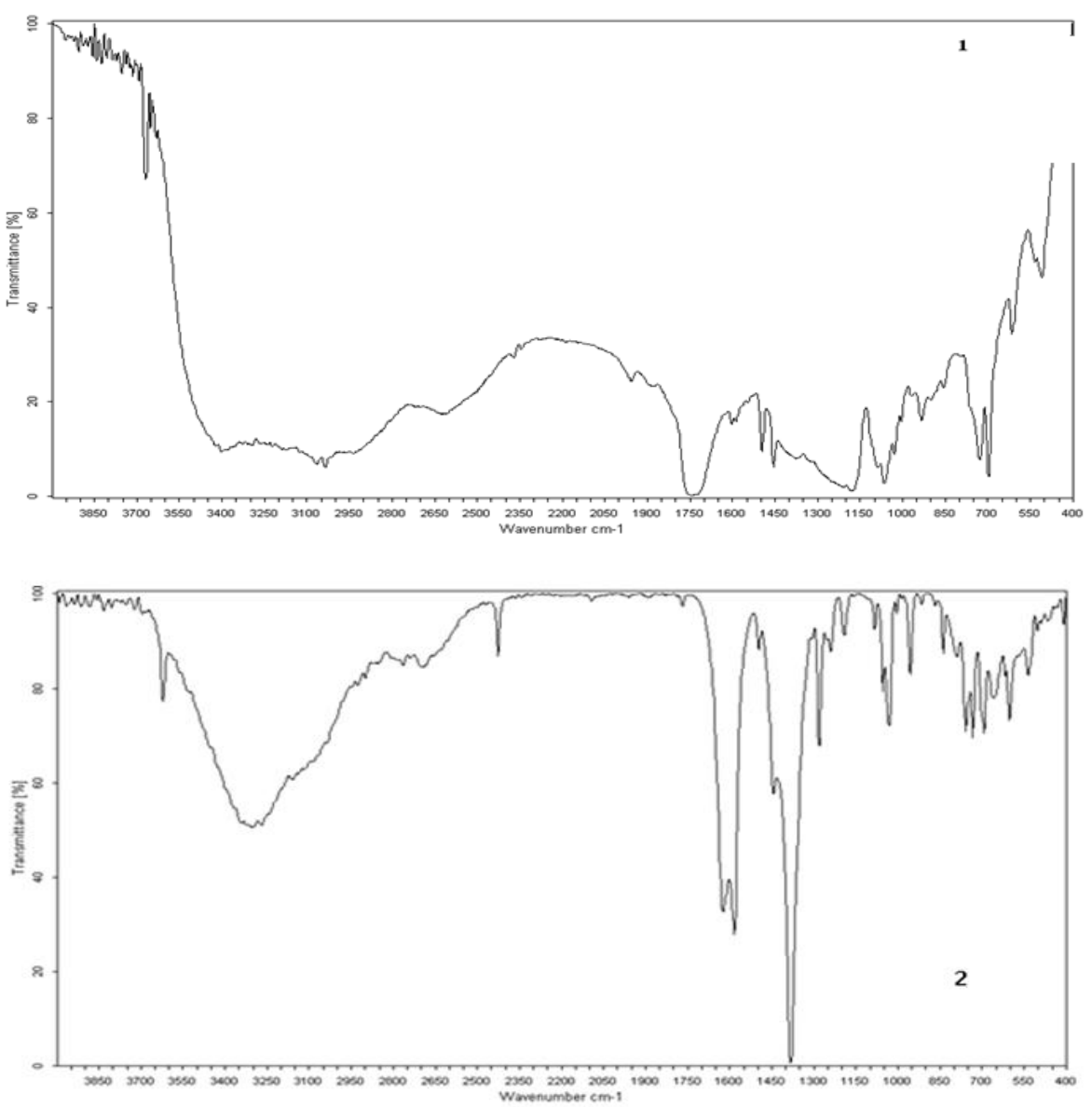

Fig. 4 : IR Spectra of Free Mandelic Acid and Its Complex

(1) free mandelic acid, (2) complex $\quad$ Gd- vs: very strog; s : strong; w : weak; vw : very weak; m: medium; mandelate, $C=5.10^{-3} M, q=2: 2, p H=6.10$ br: broad

The different interpretations of the two spectra are summarized in Table 3 based on bibliographic studies very powerful [8], [9], [2527].

Table III : Identification of Different Absorption Bands Relating to IR $\left(\mathrm{cm}^{-1}\right)$ of Free Mandelic Acid and Its Complex.

\begin{tabular}{|c|c|c|}
\hline Acide libre & $\begin{array}{l}\text { Complex } \\
\text { Gd(III) -Mandelic } \\
\text { A. }\end{array}$ & Interprétations \\
\hline $3600 \mathrm{~s}$ & $3621 \mathrm{w}$ & $v(\mathrm{OH})$ in $\alpha$ position \\
\hline $3403 \mathrm{~s}$ & -------- & $v(\mathrm{OH})$ (carboxylic function) \\
\hline $3065 \mathrm{~s} / 3037 \mathrm{~s}$ & $2691 / 2765$ & $\mathrm{v}(\mathrm{C}-\mathrm{H}) \quad($ aromatic $/ \mathrm{CH}(\alpha))$ \\
\hline $2365 \mathrm{w}$ & $2427 \mathrm{~m}$ & ---------- \\
\hline $1956 \mathrm{w}$ & $2098 \mathrm{vw}$ & $v(\mathrm{C}=\mathrm{C}) \quad($ aromatic $)$ \\
\hline 1745 vs & ----------- & $v(\mathrm{C}=\mathrm{O})$ \\
\hline --------- & 1624 vs & $v\left(\mathrm{H}_{2} \mathrm{O}\right)$ \\
\hline --------- & 1584 vs & $v(\mathrm{CC})$ \\
\hline $1603 \mathrm{w} / 1496 \mathrm{w} / 1455 \mathrm{w}$ & -------- & $v(\mathrm{CC})$ (aromatic ring $)+\delta(\mathrm{CCH})$ \\
\hline ---------- & 1384 vvs & $\delta\left(\mathrm{NO}_{2}\right)$ \\
\hline ----------- & $1281 \mathrm{~m}$ & $v_{\mathrm{as}}(\mathrm{NO})$ \\
\hline $1179 \mathrm{~s} \mathrm{~m}$ & $1192 \mathrm{w}$ & $v(\mathrm{C}-\mathrm{OH})+v(\mathrm{C}-\mathrm{O})$ \\
\hline $1066 \mathrm{~m}$ & ------- & $\mathrm{v}(\mathrm{C}-\mathrm{OH})$ \\
\hline -------- & $1034 \mathrm{~m}$ & $v\left(\mathrm{NO}_{3}\right)$ \\
\hline $1029 \mathrm{w} / 933 \mathrm{w}$ & 957 w & $\gamma(\mathrm{CCH})$ \\
\hline $729 \mathrm{~m} / 697 \mathrm{~m}$ & $760 \mathrm{~m} / 693 \mathrm{~m}$ & $\delta(-\mathrm{COO})+\gamma(\mathrm{CH})$ (aromatic ring) \\
\hline --------- & $734 \mathrm{~m}$ & $\delta(\mathrm{ONO})$ \\
\hline ----------- & $661 \mathrm{w}$ & Gd-O \\
\hline $616 \mathrm{~m} / 510 \mathrm{~m}$ & $602 \mathrm{w}$ & $v(\mathrm{CC})$ (aromatic ring) \\
\hline ----------- & $409 \mathrm{w}$ & $\mathrm{Y}(\mathrm{Gd}-\mathrm{O})\left(\mathrm{NO}_{3}\right)$ \\
\hline
\end{tabular}

Notation:

$v$ :stretching; $v_{\mathrm{as}}$ : asymmetric stretching; $v_{\mathrm{s}}$ : symmetric stretching; $\delta$ : in-plane bending; $\gamma$ :out-of-plane bending; $\omega$ : wagging; $\tau$ : twisting; $\rho$ : rocking; $\mathrm{t}$ : torsional

\subsection{Raman spectra}

In the table 4 we represented the vibration frequencies of main bands of free mandelic acid and their complex Gd-Mandelate as well as interpretations necessary based on bibliographic studies very potent [8], [9], [27], [29], [32].

Table IV : The Identification of Different Absorption Bands Relating to Raman $\left(\mathrm{cm}^{-1}\right)$ of Free Mandelic Acid and Its Complex.

\begin{tabular}{|c|c|c|}
\hline Acide libre & $\begin{array}{l}\text { Complex } \\
\text { Gd(III) -Mandelic A. }\end{array}$ & Interprétations \\
\hline$v>3600 \mathrm{vw}$ & $v>3600 \mathrm{vw}$ & $v(\mathrm{OH}) \quad(\alpha$ position $)$ \\
\hline $3450 \mathrm{vw}$ & ------ & $v(\mathrm{OH}) \quad(\mathrm{OH}$ of $\mathrm{COOH}$ function $)$ \\
\hline 3064 vs & 3065 vs & $v(\mathrm{CH}) \quad(\mathrm{C}$ in $\alpha$ position $)$ \\
\hline $3011 / 2973$ & [3013-2899] & $v(\mathrm{CH}) \quad$ (aromatic ring) \\
\hline 1719 & ------ & $v(\mathrm{C}=\mathrm{O})$ \\
\hline ------- & $1671 \mathrm{vw}$ & $v\left(\mathrm{H}_{2} \mathrm{O}\right)$ \\
\hline $1603 \mathrm{~s} / 1587 \mathrm{~m}$ & $1606 \mathrm{~s} / 1589 \mathrm{~m}$ & $\delta(\mathrm{CC})+\delta(\mathrm{C}=\mathrm{C})$ (aromatic ring) \\
\hline ------ & $1386 \mathrm{~m}$ & $\delta\left(\mathrm{NO}_{2}\right)$ \\
\hline $1296 \mathrm{w}$ & $1282 \mathrm{w}$ & $v(\mathrm{C}-\mathrm{OH})(\mathrm{C}$ in $\alpha$ position $)$ \\
\hline $1256 \mathrm{w}$ & $1258 \mathrm{w}$ & $v(\mathrm{C}-\mathrm{COO})$ \\
\hline $1223 \mathrm{w}$ & $1235 \mathrm{w}$ & $v(\mathrm{O}-\mathrm{C}=\mathrm{O})$ \\
\hline $1192 \mathrm{~m}$ & $1197 \mathrm{w}$ & $v(\mathrm{C}-\mathrm{OH})+v(\mathrm{C}-\mathrm{O})$ \\
\hline 1155 & $1157 \mathrm{w}$ & $v(\mathrm{C}-\mathrm{O})$ \\
\hline ----- & $1069 \mathrm{~s}$ & $v_{\text {as }}\left(\mathrm{NO}_{3}\right)$ \\
\hline $1030 \mathrm{~m}$ & $1032 \mathrm{~m}$ & $v(\mathrm{C}-\mathrm{COO})+\delta(\mathrm{CO})$ \\
\hline 1003 vs & 1005 vs & $\delta(\mathrm{CC})$ \\
\hline $859 \mathrm{~m}$ & $867 \mathrm{~m}$ & $\rho(\mathrm{CH})+v(\mathrm{C}-\mathrm{H})$ \\
\hline $769 \mathrm{w}$ & $791 \mathrm{w}$ & $\gamma(\mathrm{C}-\mathrm{OH})+\delta(\mathrm{CH})$ \\
\hline ------ & 726 w & $\delta(\mathrm{ONO})$ \\
\hline ------ & $666 \mathrm{~m}$ & $v(\mathrm{Gd}-\mathrm{O})$ \\
\hline $617 \mathrm{~m} / 502 \mathrm{~m} / 464 \mathrm{~m}$ & $619 \mathrm{~m}$ & $\gamma(\mathrm{C}-\mathrm{H})+\delta(\mathrm{C}-\mathrm{O})$ (aromatic ring) \\
\hline ------ & 384 w & $v(\mathrm{Gd}-\mathrm{O})\left(\mathrm{NO}_{3}\right)$ \\
\hline $337 \mathrm{w} / 213 \mathrm{w}$ & ----- & $\delta(\mathrm{O}-\mathrm{C}=\mathrm{O})+v(\mathrm{C}-\mathrm{C})$ \\
\hline -------- & $187 \mathrm{~m}$ & $v(\mathrm{Gd}-\mathrm{O})$ \\
\hline
\end{tabular}


Among the Raman spectra obtained are the free mandelic acid and its complex formed in solution, which is represented in Figure 5.
(1)
free mandelic acid,
(2) complex
Gd-

mandelate, $C=5.10^{-1} M, q=2: 2, p H=6.10$
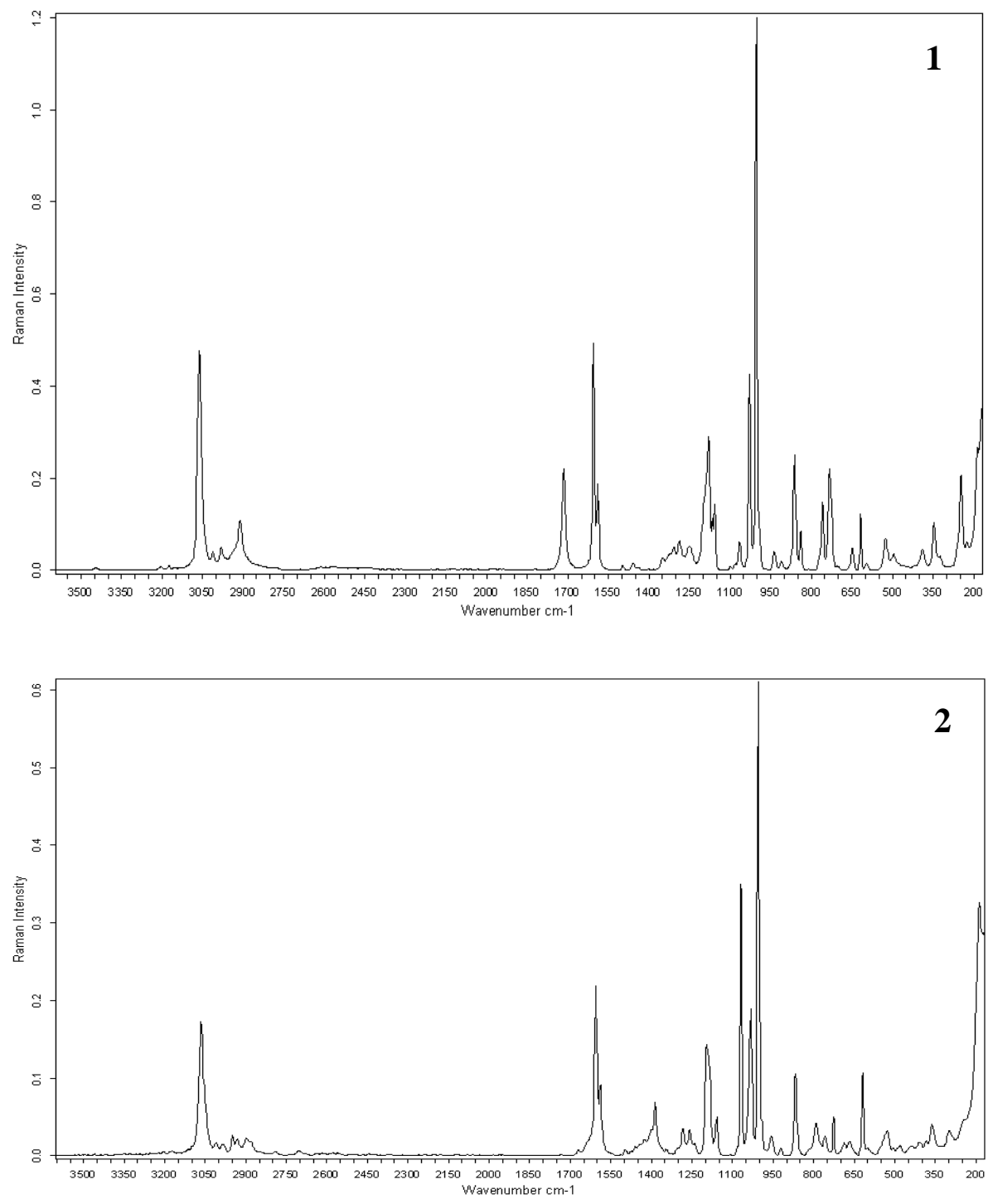

Fig. 5 : Raman Spectra of Free Mandelic Acid and Its Complex, $C=5.10^{-1} M, q=2: 2, p H=6.10$

Notation:

$v$ :stretching; $v_{\mathrm{as}}$ : asymmetric stretching; $v_{\mathrm{s}}:$ symmetric stretching; $\delta$ : in-plane bending; $\gamma$ :out-of-plane bending; $\omega$ : wagging; $\tau$ : twisting; $\rho$ : rocking; $\mathrm{t}$ : torsional

Vs: very strog; s: strong; w: weak; vw: very weak; m: medium; br: broad

The analyzes of experimental IR and Raman spectra, obtained of free and complexed forms of each acids studied, Clearly indicate that there disappearance of some characteristic bands in free acids and the appearance of new important bands in spectra of complexes Gd-Acids. The spectral data of mandelic acid $\left(\mathrm{C}_{6} \mathrm{H}_{5} \mathrm{CH}(\mathrm{OH}) \mathrm{COOH}\right)$ and its gadolinic complex; allow us to obtain an important informations on the nature of the chelating sites necessary for the formation of these coloress complexes. Only ones probable chelation sites for two acids studied are : functions carrying donor groups $-\mathrm{OH},-\mathrm{NH}_{2}$ and $-\mathrm{COOH}$. In interpretations of experimantal spectra, we insisted on the vibration bands of the main functions of the free acid and its complex (eg. mandelic acid). Indeed, experimental results show that the vibration bands of two functions $-\mathrm{OH}$ and $-\mathrm{C}=\mathrm{O}$ of the $-\mathrm{COOH}$ were completely disappeared after the formation of complexes Gd-acids, indicating that the two oxygens of the carboxylic func- tion are related to the metal $\mathrm{Gd}^{3+}$ : These results are verified by the appearance of new peaks bond vibration $\mathrm{Gd}-\mathrm{O}$ (two peaks : $675 \pm$ $40 \mathrm{~cm}^{-1}$ and $187 \mathrm{~cm}^{-1}$ ) [8], [20], [21]. Therefore the gadolinium ion is inserted into sites mononuclear polydentate. Thus, we find that the intense peak of $\mathrm{OH}$ in $\alpha$ position of the free acid (very intense peak) is reduced (weak intensity) when $\mathrm{Gd}$-mandelate complex is formed, we explained this decrease by the $\mathrm{OH}$ group is related to $\mathrm{Gd}^{3+}$ by free pair electron of oxygen without deprotonation of $\mathrm{OH}$, thus the participation of the $\mathrm{NH}_{2}$ group in $\alpha$ position by the free doublet of the nitrogen at the formation of the $\mathrm{Gd}-$ Serine complex. These results are identical with other work established for certain complexes of lanthanide ions with organic compound and amino substances [33]. In addition, there is the appearance of new peak at $1640 \pm 40 \mathrm{~cm}^{-1}$, it is the vibration of the water molecules [8], [27], [28] attached on Gd metal. The characteristic peaks of different vibrations of $\mathrm{NO}_{3}$ nitrate group were observed at wavenumbers $1386 \mathrm{~cm}^{-1} \delta\left(\mathrm{NO}_{2}\right), 1280 \pm 20 \mathrm{~cm}^{-}$ ${ }^{1} v_{\mathrm{as}}(\mathrm{NO}), 1045 \pm 25 \mathrm{~cm}^{-1} v\left(\mathrm{NO}_{3}\right)$ and $730 \pm 10 \mathrm{~cm}^{-1} \delta(\mathrm{ONO})$ [8], [20], [34], we also see the appearance of new peak at $480 \pm 35$ $\mathrm{cm}^{-1}$ related to the vibration of $\mathrm{Gd}-\mathrm{O}$ bond (oxygen of $\mathrm{NO}_{3}$ ), so, the metal $\left(\mathrm{Gd}^{3+}\right)$ is bonded to molecules of water and related group $\mathrm{NO}_{3}$. 
About spectra, it is found that the peak very intense of the free acid was decreased after the formation of complexes Gd-Acids, this is explained by the fact that the gadolinium ion congeals bonds vibrations in the case of the complexes. The absence of doubling new peaks, which appeared, gives us the idea that complexes structures are symmetrical. So the general formulas of the three characterized complexes are : $\mathrm{Gd}_{2}$ Mandelate $_{2} \cdot n \mathrm{NO}_{3} . n \mathrm{H}_{2} \mathrm{O}$

and $\mathrm{Gd}_{3}$ Serine $_{2} . n \mathrm{NO}_{3} . n \mathrm{H}_{2} \mathrm{O}$.

The number of protons $\mathrm{H}^{+}$involved in the formation of gadolinium-acids complexes is very important, and help us to know the nature of the chelation site formed in complexes, we have shown in very recent work that bidentate site does not require the intervention of a $\mathrm{H}^{+}$, against the tridentate and tetradentate sites requiring the intervention of a one proton $\left(\mathrm{H}^{+}\right)$ [8-10], [28], [34].

The complexes identified, in this work, are the type $(2,2,2)$ for system Gd-mandelate and $(3,2,4)$ for Gd-Serine complex. The set of results obtained by Indirect Photometry Detection (IPD), IRRaman spectroscopic studies and bibliographic data allowed us to propose the most probable structures for the two new complexes studied formed in aqueous solution and at $\mathrm{pH}$ range $5.50-7.50$.

\section{Propose structures}

\subsection{Structure of complex $\mathrm{Gd}_{2}(\text { Mandelate })_{2}\left(\mathrm{NO}_{3}\right) \mathrm{nH}_{2} \mathrm{O}$ type $(2,2,2)$}

Mandelic acid is à monocarboxylic acid and its formula $\mathrm{C}_{6} \mathrm{H}_{5} \mathrm{CH}(\mathrm{OH})-\mathrm{COOH}$, the probable structure for the complex formed with the gadolinium ion represented in Figure 6 :

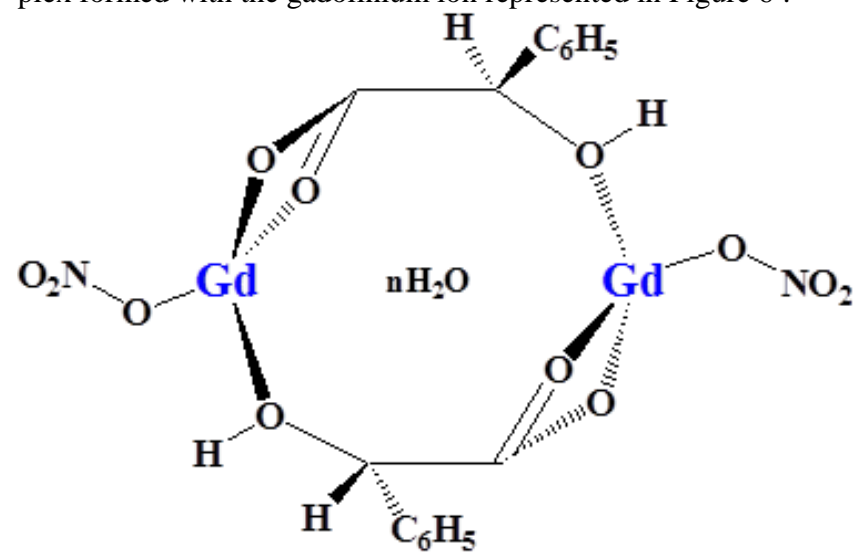

Fig. 6 : Structure of Dinuclear Complex $\mathrm{Gd}_{2}(\text { Mandelate })_{2}\left(\mathrm{NO}_{3}\right)_{2} \mathrm{nH}_{2} \mathrm{O}$

In this structure, there is formation of two identical sites tridentate mononuclear, each site requires one proton $\mathrm{H}^{+}$. The $\mathrm{OH}$ group in $\alpha$ position participate in chelations sites without protonation [9], [28], [34], [35].

This structure is the most probable, because, if we assume that the mandelate does not rotate to form this symmetrical structure, we obtained a new structure with two sites : the first one is bidentate mononuclear, that not requires $\mathrm{H}^{+}$protons ( $\mathrm{Gd}$ between $\mathrm{OH}$ in $\alpha$ position of two ligands) and the second site is mononuclear tetradentate with the intervention of one $\mathrm{H}^{+}$proton $\left(2^{\text {nd }} \mathrm{Gd}\right.$ between the four oxygens of two functions $\mathrm{COOH}$ ), that is which means the formation of this complex requires only one $\mathrm{H}^{+}$proton. Therefore, that's opposed to experimental results obtained by IPD.

\subsection{Structure of complex $\mathrm{Gd}_{2}(\text { Serine })_{2}\left(\mathrm{NO}_{3}\right)_{3} \mathrm{nH}_{2} \mathrm{O}$ type $(3,2,4)$}

The new complex obtianed by interaction with Gd(III) and amino acid « serine » is trinuclear complex and its compositions are $(3,2$, 4 ), with the intervention of four $\mathrm{H}^{+}$protons, it was explained that the high number of $\mathrm{H}^{+}$by the condensation of two gadolinium ions to form a one dinuclear hexadentate site and one mononuclea didentate site, then we propose, in figure 7 the probable structure for this trinuclear complex.

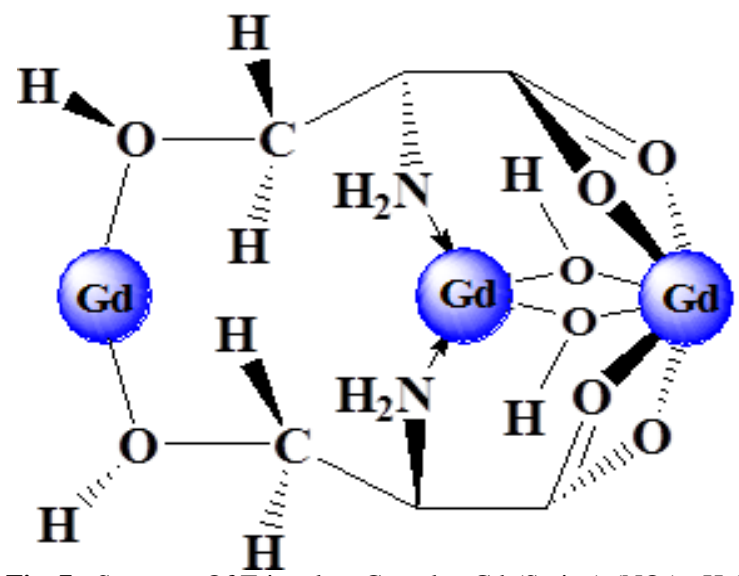

Fig. 7 : Structure Of Trinuclear Complex $\mathrm{Gd}_{2}(\text { Serine })_{2}\left(\mathrm{NO}_{3}\right)_{3} \mathrm{nH}_{2} \mathrm{O}$

This trinuclear complex with the formation of a mononuclear bidentate site ( $\mathrm{Gd}$ between two $\mathrm{OH}$ groups in $\beta$ position) and $2^{\text {nd }}$ dinuclear hexadentate (majority site) requires four $\mathrm{H}^{+}$protons, whose formation is due to the high basicity of the amine group $\mathrm{NH}_{2}$ in $\alpha$ position compared to $\mathrm{OH}$ group in $\beta$ position, the $\mathrm{OH}$ and $\mathrm{NH}_{2}$ groups in serine participate in chelations sites without protonation [8-10], [28], [33-35]. If we suppose that the serine ligand is not rotate, we obtain a trinuclear complex, but three sites are mononuclear, between them two sites mononuclear tridentate ( $\mathrm{Gd}$ between $\mathrm{OH}$ in $\beta$ position of one acid and two oxygen of $\mathrm{COOH}$ of $2^{\text {nd }}$ acid), these two sites needed one $\mathrm{H}^{+}$for esch site, is to say in a total : two protons $\left(\mathrm{H}^{+}\right)$. The third site is mononuclear bidentate (Gd between the two $-\mathrm{NH}_{2}$ in $\alpha$ position of two serine) this site does not require $\mathrm{H}^{+}$. So, in this case, there are only two $\mathrm{H}^{+}$ protons for the formation of $2^{\text {end }}$ structure. Thus, which is incompatible with the experimental results obtained by indirect photometry.

\section{Acknowledgement}

The authors are thankful to all professor in Dept. of Chemistry, Faculté of Sciences, Hassan II University for providing facilities to carry out this work.

\section{Conclusion}

We have identified, characterized and proposed structures for two new polynuclear gadolinium complexes, using three techniques : indirect photometry, IR and Raman spectroscopy. Indeed, the indirect photometry detection (IPD) was used successfully to determining the composition and the stability of these major gadolinic complexes in aqueous sulution, we obtained two type of composition $(2,2,2)$ for mandelic acid and $(3,2,4)$ for serine. The stabilities of these new godolinium complexes are $\log K_{222}=21.91 \pm 0.01$ and $\log K_{324}=43.71 \pm 0.015$ for Gd-Mandelate and Gd-Serine respectively. The results of IR and Raman spectroscopy, clearly showed that in these di and trinuclear complexes type of $\mathrm{Gd}(\mathrm{III})$ ions, all oxygens of the two ionized carboxylic functions $\left(-\mathrm{COO}^{-}\right)$, the oxygen atom of $\mathrm{OH}$ group in the $\alpha, \beta$ position and $-\mathrm{NH}_{2}$ group in $\alpha$ position of serine were involved in chelation sites. The three complexes were detected in aqueous solutions and in a $\mathrm{pH}$ region 5.50 to 7.50 , indicating that the $\mathrm{Gd}(\mathrm{III})$ ion is inserted in mononuclear and dinuclear sites. We also mentioned that the acidity of the medium has a very important role in determining the nature of the chelation site formed : tridentate and hexadentate. 


\section{References}

[1] Vogl, T. J., Pegios, W., Mahon, Mc. (1992) C.AJR, 158, 887.

[2] Thunus, L., Lejeune, R (1999) Coordination Chemistry Reviews, 184, 125. http://dx.doi.org/10.1016/S0010-8545 (98)00206-9.

[3] Rocklin, R. D, J. (1991) Chromatogr, 546, 175 http://dx.doi.org/10.1016/S0021-9673 (01)93016-X.

[4] Verchere, J. F. and Dona A. M. (1992) analusis, 20, 437.

[5] Morin, P., François, C., Dreux, M. (1994) analusis, 22, 178.

[6] Ramshing, A., Rusika, J., Hasen, E. H. (1980) Anal. Chim. Acta, 114, 165. http://dx.doi.org/10.1016/S0003-2670 (01)84288-4

[7] Riri, M., Hor, M., Kamal, O., Eljaddi, T., Benjjar, A., Hlaıbi, M (2011) Journal of Materials \& Environmental Science, 2(1), 303-308.

[8] Riri, M., Kamal, O., Eljaddi, T., Hor, M., Sefiani, N., Hlaibi, M. (2013) Analytical Chemistry an Indian Journal, 13, 41.

[9] Riri1, M., Kamal, O., Benjjar, A., Serdaoui, F., Hlaibi, M. (2013) Open Journal of Physical Chemistry, 3, 49.

[10]Hlaïbi, M., Chapelle, S., Benaissa, M., Verchere, J. F. (1995) Inorg. Chem., 34, 4434. http://dx.doi.org/10.1021/ic00121a022.

[11]Nonat, A., Gateau, C., Fries, P. H., Mazzanti, M. (2006) Chem. Eur. J., 12, 7133 http://dx.doi.org/10.1002/chem.200501390.

[12]Chatterton, N., Gateau, C., Mazzanti, M., Pecaut, J., Borel, A., Merbach, A. (2005) Journal of the Chemical Society, Dalton Transactions, 6, $1129 \mathrm{http} / / / \mathrm{dx}$.doi.org/10.1039/b416150e.

[13]Anelli, P. L., Calabi, L., De Haen, C., Lttuda, L., Lorosso, V., Maiocchi, A., Morosini, P., Uggeri, F. (1997) ACTA RADIOLOGICA, 38,125.

[14]Tsan-Hwang, C., Yun-Ming, W., Kuei-Tang, L., Gin-Chung L. (2001) Journal of the Chemical Society, Dalton Transactions, 22, 3357.

[15] Martinelli, J., Balali-Mood, B., Panizzo, R., Lythgoe, M. F., White, A J. P., Ferretti, P., Steinke, J. H. G., Vilar, R.(2010)Dalton Trans.,39,10056. http://dx.doi.org/10.1039/c0dt00815j.

[16]Moller, R. P., Sasu, K. (2010) Chemie der Erde. 70, 125. http://dx.doi.org/10.1016/j.chemer.2010.01.003.

[17]Nwe, K., Bernardo, M., Regino, C. A. S., Williams, M., Brechbiel, W. M., Bioorg. (2010)Med. Chem. 18, 5925 http://dx.doi.org/10.1016/j.bmc.2010.06.086.

[18]Lee, A. S., Lee, H. C., Jung, Y. W., Lee, J., Choi, W. J., Kim, A. K. Park, M. C.(2011) Magnetic Resonance Imaging, 29,83. http://dx.doi.org/10.1016/j.mri.2010.07.019.

[19]Moller, P. R., Knappe, A., Dulski, P., Pekdeger, A. (2011) Applied Geochemistry,

26,140 http://dx.doi.org/10.1016/j.apgeochem.2010.11.011.

[20]Kostova, I., Momekov, G., Stancheva, P. (2007) Metal-Based Drugs, doi.org/10.1155/2007/15925.

[21] Serjeant, P. E., Dempsey, B., Ionization Constants of Organic Acids in Aqueous Solution, (Pergamon, Oxford, 1979).

[22]Bjerrum, J., and al., Stability Constants, (Chemical Society, London, United Kinkdom, 1958).

[23]Langmyhr, J. F., Klausen, K. S. (1963) Analytica Chimica Acta, 29,149. http://dx.doi.org/10.1016/S0003-2670 (00)88596-7.

[24]Dona, M. A., Verchere, F. J. (1991) Analyst. 116,533 http://dx.doi.org/10.1039/an9911600533.

[25]Robert, D. J., Caserio, C. M., Problème de chimie organique moderne, (InterEditions, Paris, Fransh, 1979), p. 32

[26]Colthup, Daly, Wiberley, Introduction to Infrared and Raman Spectroscopy, (Academic Press, New York, USA, 1990)

[27]HORIBA Jobin Yvon Inc., 3880 Park Avenue, Edison, NJ 088203012. USA.

[28]Riri, M., Benajjar, A., Eljaddi, T., Sefiani, N., Touaj, K., Cherif, A., Hlaïbi, M. (2013) Journal of Materials and Environmental Science, 4,961 .

[29]Smith, E., Dent, G., Modern Raman Spectroscopy - A Practical Approach, ISBN 0-471-49668-5 (cloth : alk. paper, Wiley, New York, USA, 2005), p. 15-18

[30]Mentzen, F. B., Spectroscopies Infrarouge ET Raman - Masson, (Paris, Frensh, 1974), p. 246.

[31]Gunasekara, S., Ponnusaymy, S. (2005) Indian Journal of Pure and Applied Physics, 43,838.

[32] Sundaraganesan,N., Dominic J., B., Rajamoorthy, M., Gangadhar H., C.(2007)Indian Journal of Pure and Applied Physics, 45,969.

[33]Reid, R. S., Podanyi, B. (1987) Canadian Journal of Chemistry, 65 1508. http://dx.doi.org/10.1139/v87-258.

[34]Riri, M., Hor, M., Serdaoui, F., Hlaibi, M. (2012) Arabian Journal of Chemistry, doi: 10.1016/j.arabjc.

[35]Yang, L., Xu, X., GAO, Y., Zhang, S., Wua, J (2004) Carbohydrate Research, 339, 1679. http://dx.doi.org/10.1016/j.carres.2004.04.021. 